Legal Issues in the Digital Age. 2021. Vol. 2, no. 4.

\title{
Articles
}

Research article

UDC: 340

DOI: $10.17323 / 2713-2749.2021 .4 .3 .33$

\section{Personal Legal Status in Context of Technology-Driven Social Experiment}

\section{凡 Maria Evgenievna Cheremisinova}

Institute of Law and Comparative Legal Studies under the Government of Russian Federation, Moscow, Russia, mech.july@yandex.ru

\section{昰目 Abstract}

Based on the study of relevant research findings, law enforcement practices and content analysis, the paper identifies the peculiarities of social and legal environment reflecting the experimental nature of life of a modern society. The mutual effects of technologies, social relationships and legal regulations are discussed. It is stated that technologies which initially had an uncertain impact (social, economic, political and legal) have set an evolutionary development trend of modern societies worldwide, only to justify the insight into evolving conditions in which the personal legal status is implemented. In identifying the nature of technological revolution at the current stage, a conclusion is made on the implementation of a vast majority of social relationships in context of technology-driven social experiment. The legal features of this experiment making it different from the previous stages of the technological progress are identified, and the importance of convergence of the community and digital technologies to set directions for development of the law is underlined. Special attention is paid to the category of the personal legal status and aspects of its protection. The factors of its transformation in the given context are studied and the impact of the experiment's legal features on the personal legal status is demonstrated. The paper is aimed at proposing solutions to the issue of preserving legal status of a person as a legitimate party to social and technological processes protected from technocratic manifestations, endowed with the right of choice and opportunities to exercise it. In terms of methodology, the study is based on both general and particular research methods. The former include structured and historical methods while the latter - formal legal method and logical cognitive tools such as analysis, synthesis, induction, deduction. It is proposed to expand the field of application of legal experiment to keep pace with the social relationships dynamics in the context of technological change, help maintain the guarantees 
related to the established rights and liberties and also contribute to the development of well-balanced legal controls.

\section{O-国 Keywords}

personal legal status; technology-driven social experiment; legal experiment; interaction of law and technology; protection of individual rights in a digital age.

For citation: Cheremisinova M.E. Personal Legal Status in Context of TechnologyDriven Experiment. Legal Issues in the Digital Age. 2021, no. 4, pp. 3-33. DOI: 10.17323/2713-2749.2021.4.3.33.

\section{Introduction}

With the rapid pace of technological change social sciences and practices are increasingly faced with new problems. A powerful social impact of the advanced technologies on communities, public law and state is now clearly visible. At this stage the most active processes are those of digitization which are primarily related to the expansion of Internet as a worldwide communication and information network which has been already recognized as a social good ${ }^{1}$.

Interestingly, in its early days the Internet was viewed more narrowly as the means of communication and information, with social implications of its expanded use being unclear. However, as technologies evolved to make the Internet a space for the exercise of all fundamental rights and liberties, and as the ambiguous results of its use were assessed, the political, psychological, economic and legal roles of the Web in social and public processes including the formation of personal legal status have become evident.

The Internet's development and expansion has not only shown that modern society worldwide is open to technical innovations without asking their developers and inventors for guarantees and clear explanations of the operating principles. The convenience of use, new exciting services, innovations and economic benefits have largely overweighed the risks users assume while familiarizing themselves with the worldwide web. Meanwhile,

1 The Internet was recognized as a public good in 2011. The right to access was established by a UN declaration as a fundamental human right and a "social good". Report of the Special Rapporteur on the promotion and protection of the right to freedom of opinion and expression, Frank La Rue. 16.05. 2011. Available at: https://www2.ohchr.org/english/ bodies/hrcouncil/docs/17session/A.HRC.17.27_en.pdf) (accessed: 24.05.2020) 
these risks have turned out to be quite serious, with some spilling over into the legal field with its related institutions and mechanisms for protection of rights and liberties. The development of web technologies has set a new trend based on the system of so-called venture capital driven startups which assumes fast deployment and as fast economic return. In other words, innovations now instantly "gain ground", with the economic and social feasibility of further development of services, platforms and devices determined by users [Chugreev V.L., 2015] ${ }^{2}$. As evidenced by the adoption of strategic, conceptual and policy documents, governments are making a major focus on such a system to improve their ability to compete ${ }^{3}$.

Some authors believe that "due to the openness of modern technology, the spread of related risks and probable threats will only become possible, once it has been deployed, something that cannot be predicted as society itself is becoming a laboratory, and, unlike previously, the nature of technological development is now such that an experiment cannot be separated from use" [Bechmann G., 2012]. This observation does not only confirm close interaction and interdependence between society and technology at the current stage of evolutionary change but also outlines the conditions underlying social relationships and, thus, regulatory development. It is worth noting that the above quote is borrowed from a publication dating back to 2012. Over 10 years elapsed since then technologies have advanced exponentially, only to become part of all life spheres. The world is now at the convergence point, with technologies to include, apart from information and telecommunications, bio, nano and cognitive technologies.

Philosophical works are now concerned with the problem of forming legal consciousness and identifying new civilization development strategies, impact of the technological and cultural change on law, outcomes of human genome studies, new human improvement technologies, legal

${ }^{2}$ In the technological community there is a concept of "technical debt" to identify tasks put aside for the sake of rapid development of a new software. In many cases it means that developers will have to correct and adapt the software code.

3 See, for example: Russia: Presidential Decree No. 203 of 9 May 2017 "On the Development Strategy of Information Society in Russia in 2017-2030”; Russian Government Resolution No. 313 of 15 April 2014 "On the Approval of the Information Society State Program", National Action Plan to ensure recovery of employment and incomes of the population, economic growth and long-term structural changes in the economy (approved by the Russian Government on 23 September 2020, protocol No. 36, section VII); France: Law No. 2016-1321 of 7 October 2016 on the digital republic (government) (LOI n ${ }^{\circ} 2016-1321$ du 7 octobre 2016 pour une République numérique. Available at: https://www.legifrance. gouv.fr (accessed: 24.05.2020); international: Okinawa Charter on Global Information Society (Okinawa, 22 June 2000). 
status of cybernetic and genetically modified organisms, and artificial intelligence [Khabrieva T.Ya., Chernogor N.N., 2020]. But the assessment of implications of these processes only recently believed to be science fiction remains exclusively the focus of social sciences. Meanwhile, technologies are developing, as it were, on their own without regard for the social outcomes and "social compatibility" understood, in particular, to be the observance of human and civil rights combined with physical protection.

There is an interesting case of how inventors of nanotechnologies perceive their innovations. Thus, Eric Drexler, pioneer in this domain, has suggested to keep these technologies secret for fear of their potential threat. However, Drexler soon realized that, once he had conceived the idea of nanotechnologies, others could do the same. (In fact, as he later learned, Richard Feynman had already established the main principles in this sphere decades before). Thus, Drexler decided that the only responsible approach would be constructive control of non-reversible development of nanotechnologies [Reynolds G.H., 2003: 179-209].

As regards biotechnologies, it is stated that their unprecedented progress in the second half of the 20th century (human genome deciphering, dissemination of auxiliary reproductive technologies, organ and tissue transplanting, 3D-printing of tissues and organs, cloning, genetic testing and diagnosis, exo-skeletons etc.) has started the so-called biomedicalization of society. Moreover, the ambivalent nature of biotechnologies means that their progress brings about as many opportunities for dramatic improvement of living standards of people as there are threats caused by their tremendous potential effects on human nature [Tsomartova F.V., 2021: 9-10].

Regarding the development and deployment of artificial intelligence (AI), Max Tegmark, professor of physics at the MIT, initiator and president of two civil society institutions, Institute of Fundamental Problems and Future of Life Institute ${ }^{4}$ - has confirmed in an interview that developers of complex modern technological systems did not fully understood them. He said "unfortunately, if we are really successful in developing general AI, we will do so without understanding how it works. The alternative approach - no black boxes. Only IAI (intelligent AI approach to building AI we understand) ${ }^{5 "}$.

The above technologies which owe much of their advance to digitization and informatization have their main peculiarity in that they are fraught

${ }^{4}$ Available at: URL: https://www.livelib.ru/author/872945-maks-tegmark (accessed: 12.01.2020)

${ }^{5}$ Max Tegmark interview. Available at: https://www.youtube.com/watch?v=RL4j4 KPwNGM\&t=2s (accessed: 16.12.2019) 
with the risk of causing unfavourable social implications which are hard (or maybe impossible) to predict [Boroon L., Abedin B., Erfani E., 2021]. Examples of such implications have a delayed effect and are already reflected in law enforcement practices. As they build up, technologies of social life come under legal scrutiny, and a need to define legal aspects of technologies comes to the fore [Tikhonova S.V., 2017: 275-278]; [Spitsin I.N., 2021]. In particular, difficulties in managing personal data in the Internet did not spring up instantly, with modern legal mechanisms protecting data rights emerging as a result of the conflicts handled by courts including the supreme and supranational courts [Lazarev V.V., Gadzhiev Kh. I., 2020].

The Internet developers currently recognize a lack of data management and control in key web protocols as their "technical debt" ${ }^{6}$. However, a wide use of big data processing is now a reality, with information recognized a new economic asset along with hydrocarbons and determining the digital economic development across the board. Also, there is a problem of digital trace which needs to be studied from a perspective of respect for fundamental rights and liberties etc.

Thus, it could be asserted that the technology with initially uncertain social, economic, political and legal impact has globally set an evolutionary vector of development of modern society.

It is this feature that prompts an insight into the changing conditions which underlie the exercise of personal legal status. These conditions could be described as a large-scale technology-driven social experiment [Ceschin F., 2014]. It should be noted that in the context of this study an experiment is understood more broadly as an activity with unknown and unpredictable outcomes - not as a fixed sequence of actions and not only as a method of scientific investigation - and as a source of experience and empirical data?

${ }^{6}$ Inrupt, a company owned by the British researcher Timothy Berners-Lee, creator of the World Wide Web, has announced the issue of the proprietary corporate version of Solid, a software platform for Internet data storage and exchange, as reported by the Techcrunch. According to the platform developers, this new version will allow public authorities and businesses to develop web applications for full control of users over their data. Within the Solid ecosystem only end users will decide what data to share, with whom and on what terms. Berners-Lee believes the Internet of the future to be decentralized and free of control by Big Techs such as Facebook, Google or Amazon over the accumulated data. Available at: URL: https://www.cnews.ru/news/top/2020-11-09_otets_interneta_ predlozhil?utm_referrer $=$ https\%3A\%2F\%2Fzen.yandex.com (accessed: 12.01.2020)

7 Ideally, the method of technical experiment should exclude random factors but the social sphere which increasingly spills over into the technological one cannot be fully integrated into the ideal model of experiment. The current processes could more justifiably 
The controversial nature of the assertion will require to answer the following questions:

what makes the current experiment, once admitted to be such (a lack of its official announcement does not mean that it does not take place), so different from other technology-driven social processes of the past (including all technological achievements ranging from electric power to nuclear power generation and from space exploration to wide use of food additives);

why is it important to assert the experimental nature of innovations at this stage of development of law and legislation;

what are the legal features of technology-driven social experiment and its impact on the legal status of a person as the most vulnerable subject of social relationships;

what directions can the application of legal experiment and experimental legal regimes take.

\section{Features of the Current Technology-Driven Social Experiment and Their Manifestation in Law}

The current stage of technological revolution (TR) also described by some authors as technological change [Pashentsev D.A., Zaloilo M.V., Dorskaya A.A., 2021] differs primarily by its coverage (both in terms of the territory and the number of persons) and the pace of its dissemination, only to give rise to the problem of space-time parameters related to the exercise of law. Addressing this problem may give an answer to the question of efficiency of legal provisions to overcome the backwardness (inertia) of law and legislation compared to the pace of social and technological processes [Valverde M., 2015]. In fact, the global outreach of the Internet (as the basis of digitization and technification) owes itself to the uncertainty of its jurisdiction and enormous number of transactions per unit time in the context of its key principle of "unsolicited innovations" (making it possible to anyone, not just specialists, to change the open source code). There is a process of "innovation cycle compacting" when time between the acquisition of new knowledge and the creation and marketing of new technologies, products, services is considerably shorter.

adopt the mode of so-called random experiment based on the concept of random experience and could correspond to real-life test with a high probability that the outcome will be still unpredictable. 
This has largely determined a shorter length or a total lack of validation of innovations - a required stage of diagnostics and study of outcomes to be planned and performed in the course of any experiment in its traditional (technical and scientific) sense. This stage almost instantly spills over into legal practices where the most problematic and conflict-prone situations reflecting social responses to the use of technologies are first identified and then summarized.

Importantly, legal practices have limited potential here because of the same uncertainty of jurisdiction and problems to identify the responsible party. However it is currently the only guaranteed mechanism for protection of individuals rights and liberties which supports the emerging trend for segmentation of the web within the national borders, only to refute the hypothesis of destruction of hierarchical links between modern society and state as a result of the expansion of the global information and telecommunication network [Castells M., 2016].

What also makes the current TR so distinct is the involvement of all spheres of life - science, culture, education, health, energy, governance, business, ecology and agriculture - in the processes of digitization, something that directly impacts the personal legal status in all its manifestations. Previously, it was possible to more clearly identify a sector or other field of innovation to distinguish certain related elements (and, therefore, areas of responsibility) such as subjects, dates, outcomes etc.

Serving as an umbrella for other spheres of life, digitization now dictates the rules (including purely technical) to determine their development. While there is indeed a digital gap, inadequate coverage of the population by digital services is definitely considered to be a disadvantage and a problem to be addressed by the government. Moreover, despite the internationally declared principle of equal protection of offline and online rights, the underlying mechanisms have not been clearly defined (except traditional legal action which, as was mentioned earlier, is not always effective in the online context ${ }^{8}$ ).

${ }^{8}$ For example, according to the terms of service of social media (in 2006-2010 when they actively emerged), personal data are outside the jurisdiction of the user's (party's) state of residence. At the same time, all claims, disputes and lawsuits the user/party might bring against the social media's management are considered at the management's location. Under the terms of reference of VKontakte and Facebook, all disputes involving the management, will be governed, respectively, by the law of Russia and that of the State of California. Obviously, it is impossible for most users to take part in legal proceedings outside their state of residence. 
An important distinction of the current technology-driven social processes is informatization, that is, data-based expression and data-based documentation of all of the said processes. The data component has become an integral and to a certain extent natural and even constituting part of digitization underpinned, as one might recall, by the worldwide information and telecommunication network, only to create another risk related to inadequate knowledge of data aspects including legal ones.

Information does not only "permeates" [Tikhomirov Yu.A., Puliaeva E.V., Khludneva N.I., 2012] all spheres of social relationships to follow people through their lives but also becomes a commodity in circulation which, in its turn, is a key trait of information society [Shvetsov A.N., 2011]; [Lazarev V.V., Gadzhiev H.I., 2020: 53-79]. Meanwhile, its properties are considerably different from those of commodity. Information cannot be completely disposed off, even when it changes hands for value; it is practically indestructible; and there is no protection from its dissemination and distortion, especially in the Internet which was designed to store and transfer information without strictly pegging it to its holder.

Thus, the properties of information do not allow to confidently treat it as subject to control and regulation, that is, traditional means of ensuring the rule of law. Moreover, innovative studies in natural sciences suggest to view information as a state of aggregation of matter along with liquid, hard and gaseous states as it is quite measurable (in bits, bytes etc.) thanks to new information technologies. This hypothesis was proposed by Melvin Vopson, a British physicist, who believes that as life becomes increasingly digital, more physical matter - oil, silicon, carbon - is required to satisfy our needs in computing power and data [Vopson M., 2020]. Moreover, he has proposed to consider the bit - a unit of data measurement adopted in the digital environment - as a kind of elementary particle and estimated that in the near future there could be as many of these particles as molecules.

Even without judging the probability of such developments, it is certain that information can move from the sphere of documentation and formalization (first of all, in legal terms) of processes, phenomena, statuses, events etc. into the sphere of data features naturally attributable to a subject/object. This could cause a change in the effect of law on the information component of social relationships. This change is now hard to predict, only to raise the question of unpredictability of legal status of persons in the data environment - for example, in individual decision-making [Casey A., Niblett A., 2018] based on a large amount of personal data 
using non-transparent algorithms - which, in its turn, can contradict, as some authors believe, the fundamental principle of the rule of law [Tikhomirov Yu.A., Kashanin A.V., Churakov V.D., 2021: 86].

This can also substantiate the risk-based, experimental nature of activities in the Internet when the development of social processes is hinged on a phenomenon inadequately explored from a legal perspective. In other words, one has yet to fully understand the properties and theory of information as a whole from a perspective of traditional legal concepts and values.

Informatization and overall coverage of social relationships discussed above could be counted among the factors which define the specifics of the experiment as a technology-driven one. The social component of modern technologies has largely ensured the rapid pace of dissemination and deployment of digital innovations, and has set the development vector of economic, political and legal practices. It is the convergence of society and digital technologies that has defined the characteristics of a civilization identified as digital in recent studies [Tikhomirov Yu.A. et al., 2021]; [Kirsanov K.A., Popova S.A., 2020]; [Prohanov A.A. et al., 2020]; [Astafieva O.N., Nikonorova E.V., Shlykova O.V., 2018], only to raise the question of social implications of technological development.

Lastly, what makes the current stage of technological change really different from all previous - let's call them local - stages (in terms of spheres, territories, subjects, products etc.) is a new round of rethinking the ratio between control and freedom emerged in the course of evolution of law and legislation. This ratio might have seemed to be strongly embedded in fundamental documents on rights and liberties nationally and internationally; it assumed both self-imposed limitations of states including for protection of individuals against arbitrary action and a clearly defined measure of freedom allowing to assert a phased transition to a democratic and rights-based constitution.

Meanwhile, the development and dissemination of information technologies and formation of an information (postindustrial, programmable) society as a whole have turned out to involve complex legal processes related to reassessment of the priority of fundamental rights and liberties that might be legitimate at the time of change of a social order. It is primarily the (continued) search for balance between public and private interests which is at stake. Thus, some authors state that "despite the declared constitutional value - ensuring a balance between private and public interests - the Constitutional Court of Russia recently prioritized the protection of public 
interests as regards collection, storage and provision of people's personal data to competent officials and public authorities without their consent, as well as the requested deletion of personal data previously provided by individuals to health institutions or connected with prison sentences" [Lazarev V.V., Gadzhiev Kh.I., 2020: 45].

Active legal work is under way to address these problems. For example, the plenary resolution of the Russian Supreme Court of 20 September 2018 (No. 32) "On Amending the Plenary Resolution of the Russian Supreme Court No. 11 of 28 June 2011 "On Legal Practices on Criminal Cases Related to Extremism" features a detailed explanation of the criteria for considering and resolving cases of the said category at courts based on the right guarantee priority and with a view to the so-called pro rata principle in assessing possible restrictions [Lazarev V.V., Gadzhiev Kh. I., 2020: 107-108].

This is also compounded by other problems such as the balance between the priority of protecting freedom of speech and the right to be forgotten, the right to anonymity and the right to reliable information, the freedom of expression and the right to protection of privacy, the freedom of economic activity and the right to data protection. Apart from academic discussion on making up a new catalogue or even whole generation of rights [Talapina E.V., 2019]; [Varlamova N.V., 2019], one of the key issues of which is to substantiate the difference of innovations from the existing and established legal imperative, it is important to address the problem of maintaining the legal values and institutions established over the whole period of evolution which ensure protection of individuals rights and liberties.

In particular, the national security interests are not questioned when certain limitations are imposed on economic agents, with tighter controls perceived by them in most cases as necessary9. However, the situation is not so straightforward when, for example, determining the ratio between the right to creative freedom (or economic activity) and the right to protection of privacy.

It is worth noting a problem related to the discussions of the end of the era of privacy [Levin A., 2017]; [Rubinstein I., 2013]; [Legkodimov N.,

${ }^{9}$ In particular, the introduction of the status of critical data structure agent imposing extra duties and restrictions on private entities in communications has become legitimate as web-based services have expanded into critically important areas such as health, energy, transport etc. 
2019], with privacy, one of the core rights enshrined in today's fundamental legal documents, being "dissolved" in a new technological environment ${ }^{10}$. Despite the fairly detailed law on personal data protection and the instruction to use only anonymized data ${ }^{11}$, it has given rise to a wider problem of the so-called super (hyper) personalization [Swati S., 2019] and even individual regulation based on it [Omri Ben-Shahar, Porat A., 2021]; [Busch C., 2019].

Such novel trends both in law and social development have to be extensively studied, with the data on effects of technology (once put to use) to be accumulated, assessment of outcomes weighed etc. Meanwhile, in order to keep the established legal values, one needs to constantly refer to the legal subject category and, first of all, person as the "primary holder of activity".

The uncertainty faced by law in the digital age largely stems from problems associated with the legal subject as the primary holder of activity and the recipient of regulatory instructions not easily definable in the virtual environment due to the aforementioned reasons. The answer to the question "who has the capacity, ability and obligation to control information flows, and could be liable for implications of the use of technologies" is still to be found and, if correct, will probably determine the success of the rule of law in the digital world.

This makes it important at this stage of technological change to establish the experimental nature of processes involving the population at large and practically all legal subjects. This will allow to develop an approach matching the extent of legal and technological uncertainty around the development of society and state, and also increasing public awareness of the conditions shaped by the expansion of technological civilization.

${ }^{10}$ Art. 12 of the Universal Declaration of Human Rights (adopted by the UN General Assembly on 10 December 1948); Art. 8 of the Convention for the Protection of Human Rights and Fundamental Freedoms (ETS No. 5) (adopted in Rome on 4 November 1950); Report of the UN High Commissioner for Human Rights "The Right to Privacy in the Digital Age" (adopted on 10-28 September 2018 at the $39^{\text {th }}$ session of the UN Human Rights Council); COVID-19: Toolkit for Member States - Council of Europe. Respecting democracy, rule of law and human rights in the framework of COVID-19 sanitary crisis (SG/INF(2020)11) (adopted 7 April 2020);

${ }_{11}$ Federal Law No. 152-FZ “On Personal Data” of 27 July 2006; Roskomnadzor Order No. 996 "On Approving the Requirements and Methods for Anonymization of Personal Data" 5 September 2013; Regulation (EU) 2018/1725 of the European Parliament and of the Council on the protection of natural persons with regard to the processing of personal data by the Union institutions, bodies, offices and agencies and on the free movement of such data, and repealing Regulation (EU) No. 45/2001 and Decision No. 1247/2002/EC» (GDPR; adopted in Brussels on 23 October 2018. 
In other words, it will help overcome the arising information society paradox where despite enormous increase of data, delivery methods and the number of data exchange devices, legal subjects know so little on the essence of events, their legal status and opportunities for its protection that this questions the validity of the right to freedom of information as such (in the sense established in the constitution and internationally acknowledged).

Thus, formalization of legal subjects' "imperfect knowledge", in particular, of their legal status will give an impetus to the development of the legal basis for protection of person in an information society and will help identify the methods for legal guarantees to be ensured by public and private agents who, as parties to the experiment, will be at least willing to review, adjust and improve the products (innovations) to be developed.

Another argument confirming the experimental context of the current stage of evolution could be its transitional nature matching today's technological change closely related to social processes [Pashentsev D.A., Zaloilo M.V., Dorskaya A.A., 2021: 165]. Like any other "time of change", the current stage is characterized by distinctive instability, uncertainty and increasingly tense social relationships whose implementation depends, in particular, on the change of "players" and "rules of the game" imposed from above (or emerging in the course of self-regulation).

It may well be that such "transitional stage" will turn out to be permanent as the ongoing processes accelerate, with each structure's centenary lifecycle and 50 years of economic domination giving way to much shorter and quickly alternating periods. As a result, the only permanent thing will be changes, only to require ongoing adaptation of the legal mechanisms to innovations (probably involving a review of the legal framework).

It is worth noting that regulation of experiments is not a new thing for legal practice and primarily concerns medicine. For example, there are rules for different medical tests enshrined in special codes of good conduct (Nuremberg Code of 1947, Helsinki Declaration of 1964, Russian Code of Good Conduct in Medicine of 1994, Code of Medical Ethics of 1997). In this area, the participation conditions are at least established as regards knowledge of expected outcomes, possibility to quit the experiment at any stage, compensation in the event of negative outcome etc.

The institution of insurance can thus become especially important and gain not only applied but also deeper value-driven development since it will apply to a possibly wider range of legal subjects and life spheres involved in experimental activities. 


\section{Effect of Legal Attributes of the Experiment on Personal Legal Status}

In the current context, a number of legal attributes of such an experiment following from its social component could be distinguished. Among these, it is important to identify:

uncertain jurisdiction (as mentioned previously) which prompts a need to identify new international legal controls and which levels off the legal guarantees established within the national borders in a number of cases;

trend for erosion of responsibility, emergence of the so-called distributed responsibility matching the networking structure of the core technological resource (global network) and the special category of subjects in the experimental sphere;

"mobility" of legal statuses of the subjects who have an option to choose their own legal status depending on how the dispute develops ${ }^{12}$;

emergence of a body of new rights and liberties associated with the new technical, economic and social opportunities brought about by innovations;

combination and in some cases competition of the legal and contractual regulatory frameworks related to multipronged development of technologies and their social, primarily legal adaptation/regulation. In this context, the conventional term "contractual framework" means the rules of conduct of digital innovation users established by private subjects (developers etc.) that does not provide for freedom of action or possibility to change the terms of such contract/agreement. This is also a kind of legal attribute of the experiment requiring an insight into the nature of the "contract" to see whether it is compatible with the known private law concepts which guarantee the exercise of rights and liberties.

Identifying a jurisdiction in the Internet as the initial environment for further digitization of social life was among the first problems faced by legal theorists and practitioners. Remarkably, the fundamental international instruments in this sphere did not deal with the issues of jurisdiction despite declaring wide ranging support for expansion of digital services. Thus, the

\footnotetext{
${ }^{12}$ In this regard, a case handled by Russian courts (No. A40-18827/17-110-180) is of interest. VKontakte, a limited liability company, brought legal action against DABL, a limited liability company, for protection of exclusive related rights to a database which raised the issue of determining the special legal status of the parties which actually affected the outcome of the case.
} 
Okinawa Charter on Global Information Society provides for a need to search for effective political solutions to immediate problems such as preventing attempts of unauthorized access and dissemination of computer viruses. As a key element of its strategy, the Okinawa Charter focuses on ongoing efforts to ensure universal access and a global approach to dissemination of technologies and knowledge.

Regional segmentation of jurisdiction (within the borders of transnational associations) has likewise failed to become a general model to address jurisdiction problems as in some cases it envisaged a transfer of a part of national sovereignty, something that many countries were reluctant to do.

As a result, the Internet's national segments tend to separate, with important portals concentrating within the national domain space as confirmed by findings of cybergeographic studies [Zook M., Poorthuis A., Donohue R., 2017]. It is largely due to the fact that streamlined national mechanisms of procedural and substantive law applicable at least within the national jurisdiction still prove to be the most effective method of providing guarantees in the cyberspace.

Guarantees decline not only because of jurisdiction issues but also as a result of new approaches to the institution of legal liability which has specific features in the experimental context. While transformation affects all legal institutions across the board, legal liability is the most important of them, with the effectiveness of all other rules depending on it. The concept of so-called distributed responsibility ${ }^{13}$ to match the Internet with its distributed network-based social technological structure already assumes a lower amount of guarantees related to its implementation. The difficulty of identifying the liable (responsible) subject to enforce the performance of socially important functions is aggravated by technical backwardness of control authorities and a dilemma to what extent the authorities may interfere with natural social processes taking place on a technological platform.

While no straightforward solution to these problems has been found, there is a global trend for tighter government control which does not mean, however, that self-regulation, a characteristic trait of the innova-

${ }_{13}$ This issue was studied abroad, in particular, at the 2017 Goteborg International Conference on distributed responsibility in times of big data and the Internet of things. Available at: http://is4si-2017.org/program/workshops/distributed-responsibility-timesbig-data-internet-things/ (accessed: 25.10.2019). It was noted that there was a rapid increase of data volumes whose predictive analysis determined their impact on a wide range of spheres: military and civil surveillance, social robot technology, online economy, work, health and education, management and control of the Internet of things, intelligent road traffic control systems, intelligent power systems and a variety of financial systems. 
tion sector, has failed. Moreover, a number of large and authoritative platforms possessing adequate technological resources - for example, in the Internet - have demonstrated that their owners had quite good legal sense and in absence of rules made serious efforts to protect the rights of social media users, for example, in situations of technical failure causing a possible large-scale leakage of personal data.

Not least important is the problem of correlation between rights and duties as well as liability that is being explored from a perspective of technization of social (including legal one) life. It is this correlation that ensures a necessary degree of freedom underlying law as a whole. Moreover, it can be regarded as an element of the personal legal status which is not only a set of rights and duties but complex structural phenomenon whose effectiveness depends on the right match and mutual influence of its parts both in real life and in the process of enforcement.

The study of the institution of duties and the responsibility they assume has taken a course aimed at exploring the processes taking place in network-based and technologically distributed structures. Such structures assume building and further strengthening of horizontal links between subjects. This has given rise to the term "distributed responsibility" to be analyzed with a view to possible individualization of regulation, developing "networking" approaches to law and specific technology-driven social interactions.

Distributed responsibility (diffusion of responsibility) could be applicable to subject of legal relationships in the Internet as a distributed structure, as well as to other technization processes largely spontaneous and uncontrollable at the stage of deployment. In this case, it may be principally important to answer the question whether the mechanism for distribution of regulatory burden resulting in lower duties imposed on each subject is justified. Obviously, this will require extensive theoretical studies.

This problem has been studied internationally to place responsibility into an increasingly complex and dynamic technology-driven social environment [Simon S., 2014: 145-149] ${ }^{14}$. A special focus has been made on the responsibility attached to cognitive processes, a subject discussed in philosophy as epistemic responsibility. In this regard, two viewpoints have emerged: 1) an individualistic perspective focused on individuals within the framework of dynamic technology-driven social epistemic systems,

${ }_{14}$ This issue was at the focus of the 2017 Goteborg International Conference on distributed responsibility in times of big data and the Internet of things. Available at: http:// is4si-2017.org/program/workshops/distributed-responsibility-times-big-data-internetthings/ (accessed: 10.06.2020) 
and 2) governance perspective focused on how systems and environments should be designed to make people act responsibly (this approach is close to the prospective responsibility theory pursued in jurisprudence [Hart H.L.A., 1949]; [Saveliev Yu. M., 2015]; [Bortnikov S.P., 2012]).

The mechanisms and effectiveness of distributed responsibility of subjects should reflect the legal nature of technization processes where legitimate interests of subjects are closely intertwined and interrelated, opportunities for protection of rights and liberties are reduced due to legal and technological uncertainty while the development occurs largely through and based on self-regulation demonstrating a high degree of performance, once all parties are proactive.

Based on the studies in various fields - for example, philosophy, computer science, robot technologies and arts - there is a discussion of the need to achieve the following objectives:

formulate an adequate concept of distributed responsibility applicable to artificial systems in the future;

establish a ratio between human free will and control replaceable by non-human agents;

what this could mean for responsible application of specific technologies such as social robots, intelligent homes, civil and military drones, driverless cars or financial technologies;

how Big Data and Internet of things challenge the future of responsibility in social structures such as military command chains, social media communication, E-governments, marketing or education.

The problem of legal guarantees is directly related to the issues of efficient performance of duties and responsibilities and becomes especially urgent because of technization of social life. Besides, the issue of legal guarantees as something not explicitly incorporated by the classical theory into the legal status but believed to be inseparable from it proves to be the most complex, once we need to identify a subject capable of ensuring them.

At the same time, there is a problem of "overburdening" the legal status by making a subject already burdened with a number of functions assume more duties. This problem stems, in particular, from multiple sectoral regulation. Thus, the legal status of website owners and data dissemination organizers within the framework of legal relationships in the Internet is established by the federal law related to the information branch while that of data mediators - related to the civil branch. 
The trend for "erosion" of responsibility relates not only to the issue whether this institution fits the distributed system where digital transactions take place. It is also a consequence of the need to reduce unfavorable implications for those who generate and introduce innovations. In the context of the study, these persons could be referred to as experimenters, that is, subjects fully responsible for the start and the course of an experiment but to a lesser extent for its implications. As this trend manifests itself in the attempts to shift the burden of responsibility from the subject to the object of activity [Sinitsyn S.A., 2020], jurists are discussing a possibility to introduce legal capacity (and independent responsibility) for robotic and artificial intelligence systems etc. [Yakovlev V.F., Khabrieva T.Ya., Andreev V.K., 2017]; [Blazheev V.V., Yegorova M.A., 2021].

Lower responsibility on the part of "experimenters" can be also observed in certain terms of service of major web resources where it is said, for example, that the management of social media is not responsible for failures and data loss nor for implications of changes to functionality etc. Meanwhile, such problems are not at all exceptional: for instance, in March 2012 a software error resulted in all emails of Facebook users becoming accessible for 30 minutes while in May of the same year a security breach allowed to read users' private messages, with a vulnerability enabling hackers to easily access user profiles being later identified [Steinschaden J., 2012].

Another trend to develop an approach to responsibility is to apply the status of a high-risk source owner to developers of the so-called complex software products which affect the operation of major entities [Kryzhanovskaya A.A., 2010]. While only civil liability is meant, the approach itself reflects the context of innovative activities whose negative implications cannot be adequately predicted.

While the implications of software and hardware failures remain to be treated as risks assumed by end users, the only guarantee can now be the "right to know" that the innovative system is not optimized, that it is simultaneously tested as an experimental product and deployed while its implications may have a delayed effect and will require to be specifically studied and responded to.

The next legal feature of the current technology-driven social experiment is a situation of uncertainty faced by legislators in the process of formulating terms and definitions which determine legal statuses and modes involved in digitization. The uncertainty is due to the fact that at the time of drafting a regulation it is impossible to accurately identify the features of a subject or object involved in the innovation sector. These features may 
not be obvious to subjects themselves whose functional development follows the law of technology.

Definitions found in law - data mediator, website owner, search engine, virtual currency, blogger - while setting a general trend for associating subjects with certain areas within the innovation sector, leave open the question of who and what they cover. While a variety of opinions was expressed on each of these terms, some of them have adapted to regulation while the other did not stand the test of time and failed to become current in legal practice. In particular, Federal Law No. 97-FZ “On Data, Information Technology and Data Protection" of 5 May 2014 and specific regulations on streamlining data exchange through the use of IT networks (the so called Blogger Law) was revoked. While the term has remained, its legal definition was gone together with the law itself which turned out to be not effective enough as applied to the blogosphere.

Words such as token ${ }^{15}$, mining ${ }^{16}$, provider $^{17}$, cybersquatting ${ }^{18}$, messenger $^{19}$ can be found in regulations and enforcement documents. In some cases, the authorities have to use the terms not defined or even mentioned in the law. This reflects a new trend in legislation when a systemic approach to terminology is being transformed into a more flexible, ad hoc approach matching the extent of uncertainty, pace of technological change and to some extent the self-regulation mechanisms emerging both among economic agents and within the technological community. In this case, attaching a legal term to a subject can be considered as a starting point in

${ }^{15}$ Bank of Russia standard "Security of financial/banking transactions. Applied software interfaces. Ensuring security of financial services as openid connect client initiates authentication flow via dedicated channel. Requirements" STO BR FAPI.PAOK-1.0-2021». Came into force under Bank of Russia Order No. OD-15 of 23 July 2021.

${ }^{16}$ Chamber for Patent Disputes Opinion of 26 June 2020 (Annex to Rospatent Decision of 10 July 2020 on Application No. 2018726768/33) "On withholding state registration of the given designation as a trademark".

17 See, for example: Kemerovo Office (FAS of Russia) Resolution of 24 November 2021 on case No. 042/04/14.3-1640/2021; Yaroslavl Office (FAS of Russia) Resolution of 12 May 2021 on case No. 076/01/16-923/2020; Chuvash Republic Office (FAS of Russia) of 30 March 2021 on case No. 021/01/ 10-709/2020. It is noteworthy that while the law contains the definition of a hosting provider (para. 18, Art. 2, Federal Law No. 149-FZ "On Data, Information Technology and Data Protection" of 27 July 2006, it does not cover all features of subjects providing web services.

18 See, for example: Supreme Court of Russia Determination No. 305-ES20-16127 of 29 October 2020 on case No. A41-85820/2019.

19 See, for example: Action Plan ("roadmap") "Creating enabling environment for development of information technologies" (approved by the Russian Government on 9 September 2021). 
defining its legal status to be developed and specified rather than the final stage where the rights, duties and position in the social relationships system are clearly established.

An illustrative example of dispute resolution is the case involving V Kontakte vs. Dabl LLC ${ }^{20}$ where the defendant was able to choose its legal status by referring to loosely worded legal definitions, only to finally win the case. Once recognized as a search engine (at the retrial stage after a detailed technical examination), Dabl LLC managed to evade the liability for using the database of the plaintiff, a major national social media provider. Moreover, the defendant initially claimed to be a data mediator which coincided with the nature of its activities. However, since this line of defense did not yield definite advantages in the dispute, the argument was reversed.

The personal legal status - in this case, that of the V Kontakte users was also indirectly invoked as the defendant claimed its rights to the data base built up to a large extent with the data users upload to their pages. The question of protecting user rights where the data posted to a social media is used by a third party (in this case, the defendant) was not further explored because the lawsuit alleged violation of exclusive rights to the database. This shows an ambiguous position of users who are not simply recipients of a service but legitimate parties to the data exchange, with the value of the resource (in this case, a social media) as a whole depending on their number and engagement.

This functional "mobility" of the parties to the information process will also determine the mobility of their legal statuses manifested in the multistakeholderism principle applicable primarily to the virtual space. In a wider sense this principle can also be used in the technological innovation sector. It is characterized by a high degree of interdependence of subjects engaged in web-based activities. On 10 June 2019 the Secretary General's High-Level Panel of Digital Cooperation published a report entitled "The Age of Digital Interdependence" in which it was noted that as computer technologies develop, increasingly more users join the worldwide web, with the number of transnational linkages growing annually. Moreover, the report stressed the transformational impact of digital technologies on social, economic, political and cultural spheres of life, that is, those laying the foundation for human development.

Due to a high degree of subjects' interdependence and mutual influence, their legal statuses become transformed as a result of:

${ }^{20}$ Case No. A40-18827/17-110-180. 
combination (for example, when technical capability and control functions are combined depending on technical capabilities to affect technological processes or when the use of innovations becomes creative to the point that one becomes able to independently develop a technology, in particular, based on open source codes);

intensification due to a need to perform public functions to maintain law and order and ensure data and national security. This is clearly manifested in the performance of public duties and responsibilities when private law subjects assume certain functions, for example, to participate in the protection of key infrastructure or training exercises involving activities to perform training missions in a specific situation of threat to sustainability, security and integrity of web operations;

coalescence $^{21}$ (merger of elements within a mobile environment) where the features and functional association of specific types of subjects cannot be clearly identified due to wide legal definitions applicable to them. Because it was the data sector that gave a decisive impetus to the current technological advance, a relevant example could be the situation where the same subject combines the statuses of a website owner, data mediator, data dissemination organizer and search engine. The said statuses could be established in different branches of law (data law for website owners, civil law for data mediators) but involve legislative regulation of subject's activities in the global information and telecommunication network.

The trend for "mobility" of legal statuses involving their transformation will require further research, first of all theoretical, to propose justified criteria of such transformation, preserve the historically established legal values and develop new legal mechanisms abreast of time.

Regarding the transformation criteria of the legal status of subjects (that is, the indicators capable of justifying this transformation from social, legal, technological perspectives) the following could be proposed:

conformity with statutory principles and provisions;

${ }^{21}$ The term "coalescence" is used to underline the difference between the processes of merger and combination of legal statuses. Coalescence is a merger within a structure represented in this study by the legal status of a subject who simultaneously performs the functions, for example, of the website owner, data mediator and data dissemination organizer. In contrast, combination takes place when one group of subjects is able to perform the functions of the other, that is, when the legal status emerges as a result of simultaneous performance of support and control functions as well as a result of network use. This transformation of legal status becomes transversal, as it were, and is regarded in view of prior categorization of subjects as persons who use, support and control the Internet. 
changing role in the system of legal relationships (in particular, an increase in technical capability support or control functions);

opportunity to control technological processes related to the exercise of the rights and duties of subjects;

clear identification of the purpose of transforming a subject's legal status in view of legitimate interests of other subjects;

degree of influence (economic, political, information, technological) on the legal status of other subjects;

degree of the subject's vulnerability to technological (information, political etc.) impact.

While the process of transformation of legal status can affect rights and duties (in the form of both contractual and legislative regulation), the legitimate interests (as a conceptually identified element of the legal status) should be preserved and cannot be subject to outside change because they essentially reflect the subject's internal motivation.

A study of the emergence of a body of new rights and liberties as a feature of the experimental state of society merits a special focus. New technical, economic and social opportunities created by innovations invariably bring about new rights. Many policy definitions of rights contain a key word "opportunities" as something potentially able of being translated into rights.

However, not all opportunities are backed by guarantees and clearly correlate with duties - far from it - since they require to identify the respective responsible subject. While factors of such transformation need to be carefully established in the theory, it is already possible to identify among them the social justification and the implementation of legitimate interests and opportunities of specific subjects (both public authorities and private individuals) to guarantee these rights.

The widespread term digital rights used domestically in the Civil Code of Russia obviously has a wider connotation and applies to a broad range of rights and liberties exercised in the Internet.

The rights related exclusively to the emergence of Internet and development of social relationships in a digital environment include:

Internet access right as a whole (as a result of the general and presumably global trend for digitization, the Internet was recognized a social good and it was proposed to establish the statutory right of online access which 
explicitly assumes the government's involvement in order to be guaranteed. This issue is still debated, especially in the context of pandemic when the importance of the global web has grown exponentially as more user transactions went online. Moreover, the Internet demonstrated the willingness to increase the data traffic (data on major operating failures even during the total lockdown when a large part of the population had to work remotely) and proved to be technically fit to make up for the lack of physical interaction. But while the technical and organizational conditions to formalize the right of access are there, a high degree of uncertainty around the web development prospects does not yet allow to propose a straightforward approach to establishing such a right;

data protection right (discussed due to the exponential increase of volume and detail of data whose psychological and social impact is yet to be adequately studied but negative implications are already there. These implications call for a "search" for certain new opportunities for users to establish the rule of law in the virtual environment. In this case, the right can be characterized as a justified claim from a perspective of the non-classical theory which complements and expands the understanding of the object of rights [Tumanova A.S., Kiselev R.V., 2011: 41]; [Heffe O., 1994: 248]);

network neutrality enabling right (that is, technically ensuring the same data delivery quality irrespective of the content, meaning, addressee etc. As the network neutrality principle is being recognized as important for overall system operation, it is gradually moving from self-regulation (as this opportunity was initially there) to the legislative sphere capable of better securing this opportunity ${ }^{22}$ );

right to a domain name (covering a large number of private law issues while being related exclusively to the worldwide web's architecture);

subject's right to manage personal data in the Internet (actually meant to make up for the aforementioned "technical debt" reflecting a lack of opportunities to exercise the established rights such as the data or privacy protection right) $)^{23}$.

${ }^{22}$ For example, Law of Brazil No. 12.9652014 of 23 April 2014 has established a system of civil rights in the Internet (Marco Civil da Internet).

${ }^{23}$ This conclusion could be confirmed by the emerging trend to change data management policy in the Internet as the most urgent problem for protection of digital rights and liberties. Inrupt, a company owned by the British scientist Timothy Berners-Lee, creator of the World Wide Web, has announced the launch of a corporate version of its software platform which, as developers claim, will allow users to gain full control of their own data. Within this ecosystem only end users will decide, what data to share, with whom and on what terms. The scientist believes the Internet of the future to be decentralized, that is, 
We believe digital rights and liberties can be defined as broader opportunities for individual and collective subjects to exercise the whole range of acknowledged rights and liberties, as well as new opportunities (justified claims) for acquiring tangible and non-tangible goods through legitimate use of the global information and telecommunication network.

The nature of such rights is predetermined both legally and contractually, that is, combines public and private law principles of emergence and regulation, as well as technological peculiarities of Internet operations, only to result in certain risks involved in their protection.

A combination of public and private law principles applicable to regulation of social relationships related to the innovation sector as a juridical feature of the current technology-driven social experiment leads to a model conventionally called "supervised self-regulation". The current explosion of new ICTs largely owes itself to freedom of private enterprise. At the early "testing" stage this form of expansion involving minimum restrictions was justified and convenient.

However, as innovations spread out the initially achieved success has brought about the awareness of the underlying complications and a need for regulation by public authorities. This issue is also raised by representatives of the technological community apparently willing to adopt regulatory mechanisms capable of adapting the algorithms to society and thus contribute to further development of science. A skeptical attitude to the applicability of legal controls to the technological sector should (and gradually does) give way to the awareness of the need for cooperation between technologies and jurisprudence. Both are the evolutionary achievements of humanity and cannot prevail in modern society possessing adequate historical experience of overcoming any pressure which stands in the way of natural social development.

A certain competition between regulatory principles of public and private law can still be observed as mainly manifested in restrictions which, once introduced, do not always prove to be as effective as expected ${ }^{24}$.

While the search for effective legal mechanisms continues, self-regulation is proposing new solutions to the problems which the law has failed to address. For example, the problem of ensuring exclusive rights to works

free of control by Big Techs such as Facebook, Google or Amazon over the accumulated data. Available at: URL: https://www.cnews.ru/news/top/2020-11-09_otets_interneta_ predlozhil?utm_referrer=https\%3A\%2F\%2Fzen.yandex.com (accessed: 10.06.2020)

${ }^{24}$ The high-profile cases include the attempts to impose restrictions on Telegram and Twitter as well as penalties on Facebook and Google. 
posted online has been partially solved by developing and deploying convenient and accessible platforms proposing content of high quality. Legal provisions and even special institutional mechanisms (such as web police) aimed at prohibiting the circulation of pirated products are also applicable but obviously unable to fully reverse the situation and put it under control.

The attempts to address the issue of web content inheritance is also of interest. While it is still debated among jurists whether to include it into the mass of the succession, treat as tangible or intangible asset (no straightforward answer is there yet), Apple has developed the Digital Legacy function which provides for transfer of data from iCloud to one of the user's trustees in the event of his death.

Thus, the regulation of technologies is still be based on self-regulation taking into account legal formulas which "identify" the problems of adapting technologies to social relationships and set the general trend for addressing the urgent problems of using the expanded capabilities of technological innovations.

The competition of public and private law regulatory mechanisms is gradually giving way to their combination in specific areas of social relationships which is expected to help balance all vested interests involved in adoption of innovations. Moreover, there is a need to preserve the personal legal status as a key indicator reflecting the justification and usefulness of introducing controls in the context of technological change. The acknowledgement of experimental nature of activities will allow not only maintain the existing rights and liberties but also possibly expand their range by introducing more legal guarantees.

\section{Conclusions}

Identifying legal features of the experiment under way in all spheres of life is primarily aimed at developing legal mechanisms to regulate social relationships in this context. In this case, the introduction of experimental legal regimes increasingly present in the innovation sector is legitimate and logical. This method of regulation is now necessary and justified while any criticism that legislative imperatives will weaken since public institutions will be unable to take decisions with confidence during the active use of legal experiment is irrelevant as it does not reflect the specifics of general conditions of existence of the state and society.

The problems previously identified in jurisprudence are still there including difficulties of implementing the idea of a legal experiment related to the need to simulate the real legal environment to test proposed solu- 
tions (the environmental aspect being definitely vital for the technology sector) and to choose hypotheses to review decisions, assessment criteria etc. [Tikhomirov Yu.A., 2015: 83]. Still unresolved is the problem of distinguishing the impact of experimental factor as such [Yeltsov V.N., 2009], with the issue of legal experiment, its functions, possible limits, special legal guarantees for those affected, clear criteria of when such experiments are useful or necessary yet to be properly studied [Motin S.V., 1999].

At the same time, progress in this sphere is obvious. The adoption of Federal Law No. 258-FZ "On Experimental Legal Regimes in the Digital Innovation Area in Russia" of 31 July 2020 has been a major step towards legal accommodation of experimental activities and understanding them from a perspective of law.

The law is largely directed at corporate agents of innovation, subjects of the experimental legal regime (as defined by the law). Meanwhile, it also covers the personal legal status in a wider sense by establishing the category of "participants to the experimental legal regime" to distinguish the legal status of those initiating an experiment and those directly involved in it, that is, validating new goods and services.

As the first principle of an experimental legal regime specified in the law, it is forbidden to restrict the statutory rights and liberties of individuals, compromise the common economic space in the territory of the Russian Federation or otherwise reduce the right protection guarantees of individuals and legal entities envisaged by the Art. 4 of the Constitution and other national regulations.

This provision confirms the importance of the effective legal provisions in an experimental environment, as well as defines the peculiarities of experimental conditions themselves which require regulation with regard to dates and territory of the experiment (part 3, Art. 6, Art. 7), due regard for the risks related to the use of innovations (p. 4, part 5, Art. 10), compensation of damage to health of individuals or property of legal entities as a result of experimental legal regime including those caused by legitimate actions of subjects to the experimental legal regime (part 4, Art. 5).

Importantly, the law allows to avoid entering into relationships with subjects of an experimental legal regime and to introduce extra guarantees for protecting the rights of those entering into such legal relationships including advice of special regulation (part 7, Art. 5).

Such provisions already reflect the fact the law recognizes experimental nature of activities and of legal status of subjects able later to transform into a full legal status to ensure adequate protection of persons, society and state. 
Further development prospects of such approach can involve more variable use of legal experiments. For example, it has been proposed to make virtual worlds a place for testing certain legal formulas for the real world while legal simulators can prove to be useful for "laboratory testing" and more effective, safe and secure real world introduction of certain provisions. Such simulation has been conducted so far experimentally in the area of social science and humanities [Baturin Yu.M., 2017: 27-35].

We believe a broader application field of the legal experiment will respond to the pace of changing social relationships in the context of technological change, help maintain the guarantees of the established rights and liberties, and contribute to the development of well-balanced legal controls.

Moreover, such a system, with analogue communications being preserved, will help overcome an overall negative perception of technology as a dangerous, unexplored and risk-prone phenomenon offering no chance of influence because of its mysterious essence [Heidegger M., 1993]. These concerns were expressed by Martin Heidegger who considered technology to be a resource and a functional element of supply production, only to show that man and nature become resources themselves and thus refute a widespread belief that man is a master of technology and nature and that technology has no impact on nature.

Still more important is to understand the process of transformation of personal legal status from a perspective of future philosophy of law whose emergence will influence the status of persons as legitimate parties to all social and technological processes protected from arbitrary technocratic action and endowed with the right of choice and opportunities to exercise it.

In this case, the personal legal status will be indicative of evolutionary path of modern society capable of further existence, cured from mistakes of the past and protected from future crises.

A stronger focus on the institution of personal legal status, especially in the current uncertain context, is meant to prevent persons from being permanently and fully (or even partially) transformed into test subjects deprived of protection and adequate information of what is going on, and to avoid the worst case scenarios including the aggravation of social and political conflicts and loss of human capital accumulated over centuries and driving the development of legal institutions and provisions.

At the same time, it would be unreasonable to restrict the right of developers to commercialize the outcomes of innovations since it contradicts the principles of progress and could undermine competition and civil 
action. It has been underlined in research papers that further efforts are required to search for legal controls that would encourage the high tech development. They should also more adequately unlock the principles and mechanisms of public-private partnership - involvement of the government and businesses in joint projects which neither the government or businesses could implement on their own. These include, in particular, the projects in the area of information and communication and new technologies [Khabrieva T.Ya., 2012: 20].

One could possibly suggest the juridification of technologies involving close cooperation between representatives of the technological and legal communities which ideally should be promoted on the basis of recognition of the priority of the personal rights and liberties.

\section{†国 References}

1. Abliazov N. (2017) The technological singularity. A study of conditions of emergence and implications for humanity. Available at: URL: https:// mipt.ru/education/chair/philosophy/publications/aspers/a_1xes5v.php (In Russ.).

2. Astafieva O.N., Nikonorova E.V., Shlykova O.V. (2018) The digital civilization culture: new stage of the understanding of future sustainable development strategies. The cultural observatory. no. 15(5), pp. 516-531. Available at: URL: https://doi.org/10.25281/2072-3156-2018-15-5516-531 (In Russ.).

3. Baturin Yu.M. (2017) Legal violations in online worlds and experimental jurisprudence. In: Papers of international research workshop "Security, conflicts and fight against extremism in Internet: legal aspects". Moscow. P. 27-35. (In Russ.).

4. Bechmann G. (2012) Modern Society: risk-prone, information and knowledge society. Moscow: Norma. 247 p. (In Russ.).

5. Big data interpretation and application in jurisprudence and legal practice (2021) Yu.A. Tikhomirov, A.V. Kashanin, V.D. Churakov et al. Moscow: Yustitsinform. 188 p. (In Russ.).

6. Bortnikov S.P. (2012) The prospective and retrospective responsibility. Ekonomika i pravo = Economy and Law, no. 12, p. 47-50 (In Russ.).

7. Boroon L. et al. (2021) The Dark Side of Using Online Social Networks: A Review of Individuals Negative Experiences. DOI: 10.4018/ JGIM.20211101.oa34. Available at: https://www.igi-global.com/article/ the-dark-side-of-using-online-social-networks/276942

8. Busch C. (2020) Implementing Personalized Law: Personalized Disclosures in Consumer Law and Data Privacy Law. Available at: https:// 
lawreview.uchicago.edu/publication/implementing-personalized-lawpersonalized-disclosures-consumer-law-and-data-privacy-law

9. Casey A.A. (2018) Framework for the New Personalization of Law. Computer Science. Law \& Society: Legal Profession. Available at: https://www.semanticscholar.org/paper/A-Framework-for-the-NewPersonalization-of-Law-Casey-Niblett/d0f4605c180ce64d0ff5dba7705a5101a0f0c741

10. Castels M. (2016) The power of communication. Moscow: Higher School of Economics. 564 p. (In Russ.).

11. Ceschin F. (2014) How the Design of Socio-technical Experiments Can Enable Radical Changes for Sustainability. International Journal of Design, vol. 8, no. 3. Available at: http://www.ijdesign.org/index.php/ IJDesign/article/view/1308/650

12. Churgeev V.L. (2015) The technical debt in innovative software projects. Problemy territorialnogo razvitia $=$ Territorial development issues, no. 2 (22). Available at: URL: https://cyberleninka.ru/article/n/ tehnicheskiy-dolg-v-programmnyh-proektah-innovatsionnogo-tipa/ viewer

13. Data protection: comments to legal practices (2020) V.V. Lazarev et al. Moscow: Kontrakt. 174 p. (In Russ.).

14. Digital civilization (2020) Media communications. Web marketing. Lobodenko L., Shesterkina L. et al. Chelyabinsk: University. 770 p.(In Russ.).

15. Digital civilization (2018) Russian and the 21th century electronic world. Prokhanov A.A. et al. Moscow: Knizhny Mir. 288 p. (In Russ.).

16. Digital law (2021) V.V. Blazheev, M.A. Yegorova et al. Moscow: Prospekt. 640 p. (In Russ.).

17. Hart H.L.A. (1949) The Ascription of Responsibility and Rights. Proceedings of the Aristotelian Society, vol. 49, pp. 171-194.

18. Heffe O. (1994) Politics. Law. Justice. The foundations of critical philosophy of law and state. Moscow: Gnosis Publishers. 319 p. (In Russ.).

19. Heidegger M. (1993) The question of technology. In: The Coming Technological Singularity: how to Survive in the Post-Human Era. Available at: http://www-rohan.sdsu.edu/faculty/vinge/misc/singularity.html

20. Kirsanov K.A., Popova S.A. (2020) Digital civilization. Mirovye civilizaccii $=$ Civilizations of the world, no. 1-2. (In Russ.).

21. Khabrieva T.Ya., Chernogor N.N. Future of Law (2020) Moscow: Norma 174 p. (In Russ.).

22. Kryzhanovskaya A.A. (2010) Civil liability for the damage caused by complex software products. Moscow: Norma, 160 p. (In Russ.). 
23. Law and biomedicine (2021) F.V. Tsomartova (ed.). Moscow: Norma. 136 p. (In Russ.).

24. Legal capacity: legal analysis (2017) Papers of XII annual scholar readings. V.F. Yakovlev, T.Ya. Khabrieva, V.K. Andreev et al. Moscow: Statut. 434 p. (In Russ.).

25. Legal environment and man (2012) N.V. Vlasova, S.A. Gracheva, M.A. Mescheryakova et al. Moscow: Yurispridentsia. 249 p. (In Russ.).

26. Legkodimov N. (2019) End of the privacy age. Vedomosti. = News, 9 July. Available at: URL: https://www.vedomosti.ru/opinion/ articles/2019/07/09/806225-konets-privatnoi-epohi. (In Russ.).

27. Lessing L. (2017) Vast online games need a political structure. Available at: https://mmozg.net/mmo/2017/06/06/professor-lourens-lessing-onlaynovym-mir am-neobhodimapoliticheskaya-sistema.html

28. Levin A. (2017) Has the Era of Privacy Come to an End? Canadian journal of law and technology, vol. 15, no. 1. Available at: https://digitalcommons.schulichlaw.dal.ca/cjlt/vol15/iss1/2/

29. Medvedovsky I. (2016) The age of hackers: why privacy is gone for good. Available at: URL: https://www.rbc.ru/opinions/technology_and_ media/01/04/2016/56fe59b79a7947bb7cf4b4e4. (In Russ.)

30. Misostishhov T.Z. (2020) The personalized rights and fundamental rights. Cifrovoe pravo = Digital right, no. 1, pp. 56-73. Available at: https://doi.org/10.38044/2686-9136-2020-1-4-56-73

31. Motin S.V. (1999) Experimental method in the social and legal environment. Candidate of Juridical Sciences Summary. Moscow, 24 p. (In Russ.).

32. Omri B., Porat A. (2021) Personalized Law Different Rules for Different People. N.Y.: Oxford University Press. 256 p.

33. Pashentsev D.A., Zaloilo M.V., Dorskaya A.A. (2021) Technological change and legal development of Russia. Moscow: Norma. (In Russ.).

34. Reynolds G. (2003) Nanotechnology and Regulatory Policy: Three Futures Harvard Journal of Law and Technology, vol. 17, no. 1, pp. 180-209.

35. Rubinstein I. (2013) Big Data: The End of Privacy or a New Beginning? International Data Privacy Law, vol. 3, no. 2.

36. Saveliev Yu.M. (2015) Concept of legal responsibility. Pravovye issledovania $=$ Legal Studies, no. 10. pp. 61-80. DOI: 10.7256/24097136.2015.10.1612. Available at: URL: https://nbpublish.com/library_ read_article.php?id = 16122. (In Russ.).

37. Shaw J. (2009) The erosion of privacy in the Internet era. Available at: https://www.harvardmagazine.com/2009/09/privacy-erosion-ininternet-era 
38. Shvetsov A.N. (2011) Information society: theory and practice of the emergence in Russia and worldwide. Moscow: URSS. 277 p. (In Russ.).

39. Sinitsin C.A. (2020) The Russian and international civil law in the context of robotization and digitization. Moscow: Infotropic. 256 p. (In Russ.).

40. Simon S. (2014) Distributed Epistemic Responsibility in a Hyperconnected Era. The Onlife Manifesto, pp. 145-159.

41. Spitsin I.N. (2021) Juridification of artificial intelligence concept and limits of using Al technology at court. Lex Russica = Russian Law, no. 10. (In Russ.).

42. Steinschaden J.(2011) Social media. Facebook phenomenon. Moscow

43. Swati S. (2019) Privacy versus personalization. Available at: https:// www.the-future-of-commerce.com/2019/01/28/privacy-versus-personalization/

44. Talapina E.B. (2019) The evolution of human rights in a digital age. Papers of the Institute of State and Law, no. 3,122-146 p. (In Russ.).

45. Tikhomirov Yu.A. (2015) Law: prospects and risks. Moscow: Norma. (In Russ.)

46. Tikhomirov Yu., Kichigin N. et al. (2021) Law and Digital Transformation. Legal Issues in the Digital Age, vol. 2, no. 2. (In Russ.).

47. Tikhonova S.V. (2017) Juridization of ICT as a driving factor of e-government. Guarantees of Human Rights and Liberties in Today's World: workshop papers. Moscow: Prospect. p. 275-278 (In Russ.).

48. Tumanova A.S., Kiselev R.V. (2011) Human rights in legal theory and legislation of Russia, second half of 19-early 20 century. Moscow: HSE. (In Russ.).

49. Valverde M. (2015) Chronotopes of Law: Jurisdiction, Scale and Governance. L.: Routledge. P. 668-673.

50. Varlamova N.V. (2019) Digital rights: new generation of human rights? Collected works of Institute of State and Law, vol. 14, no. 4. (In Russ.).

51. Vopson M. (1994) The information catastrophe. Available at: URL: https://zen.yandex.ru/media/htech_plus/fizik-melvin-vopson-temnaiamateriia-mojet-byt-informaciei-5f3637ae40616c4c6b9682f1

52. Yeltsov V.N. (2009) Legal experiment in modern Russia. Candidate of Juridical Sciences Summary. Tambov, 25 p. (In Russ.).

53. Zook M., Poorthuis A., Donohue R. (2017) Mapping Spaces: Cartographic Representations of Online Data. In: Handbook of Online Research Methods. 


\section{Information about the author:}

M.E. Cheremisinova - Candidate of Sciences (Law), Senior Researcher.

The article was submitted 12.07.2021; approved after reviewing 11.10.2021; accepted for publication 01.11.2021 